Historic, archived document

Do not assume content reflects current scientific knowledge, policies, or practices. 



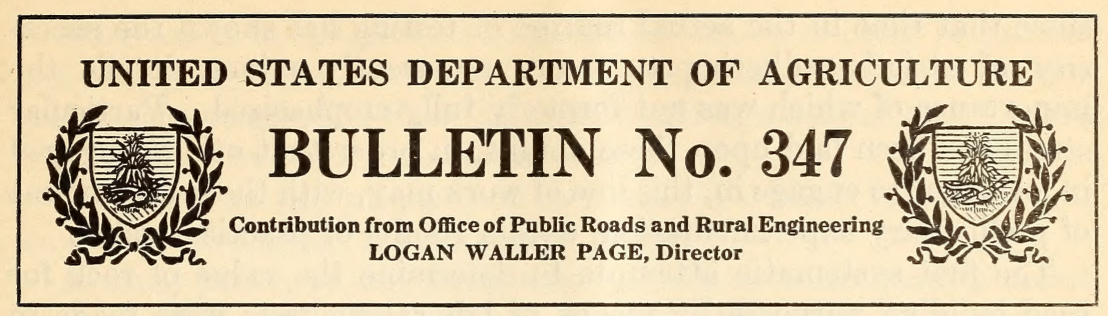

Washington, D. C.

PROFESSIONAL PAPER

March 17, 1916

\section{METHODS FOR THE DETERMINATION OF THE PHYSICAL PROPERTIES OF ROAD-BUILDING ROCK.}

By Frank H. Jackson, Jr., Assistant Testing Engineer.

CONTENTS.

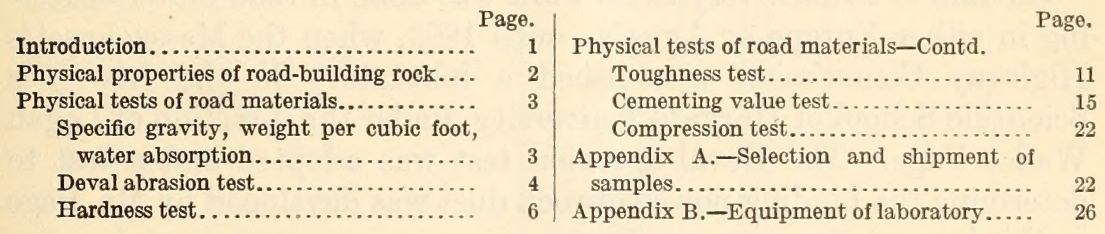

\section{INTRODUCTION.}

This bulletin is a partial revision of a former bulletin by Albert T. Goldbeck and Frank H. Jackson, jr., issued June 10, 1912. ${ }^{1}$ The first bulletin dealt not only with the method of testing rock for road building, but also gave the results of laboratory tests obtained by the office on all rock samples received to July 1, 1911, together with the interpretation of those tests. It appears advisable to present complete results of tests by the office at rather frequent intervals, so that additional data may be promptly available for the general use of highway engineers. The present bulletin has thus been limited to a description of methods employed by this office for testing rock for road building, and is intended to serve as a more or less permanent laboratory manual for those who have occasion to make such tests.

Although the methods of determining the physical properties of rock used in macadam road construction have remained essentially the same since the publication of Bulletin 44, experience gained

1 Office of Public Roads Bulletin No. 44, The Physical Testing of Rock for Road Building.

$17025^{\circ}-$ Bull. $347-16-1$ 
since that time in the actual routine of testing has shown the necessity of strictly adhering to many apparently minor details the importance of which was not formerly fully emphasized. Particular stress has been laid upon these details, in order that others engaged in, or about to engage in, this line of work may, with the least amount of preliminary experimentation, obtain results of practical value.

The first systematic attempts to determine the value of rock for road-building purposes by means of laboratory tests were made in France, where in 1878 a road-material laboratory was founded in the French School of Bridges and Roads at Paris. Here the Deval abrasion test was adopted, and this test with slight modification has been accepted as standard throughout the United States. The test is named from its inventor and was first used in connection with contract work in the city of Paris. Many valuable data were also collected in this laboratory on the hardness and toughness of rock, and tests for these properties were developed which were, in principle, the same as those in use to-day.

Outside of France very little work was done in road-material testing in either Europe or America until 1893, when the Massachusetts Highway Commission established a laboratory in the Lawrence Scientific School of Harvard University, under the direction of Logan Waller Page. The Deval abrasion test was adopted and a test to determine the binding power of rock dust was developed by Mr. Page in this laboratory.

In December, 1900, the United States Government established a laboratory in the Bureau of Chemistry of the Department of Agriculture, under the direction of Mr. Page. This laboratory became in 1905 a part of the Division of Tests of the newly organized Federal Office of Public Roads. On July 1, 1915, during a general reorganization, it was placed in the Division of Road Material Tests and Research of the new Office of Public Roads and Rural Engineering. The recent general interest in road improvement has also resulted in the establishment of many laboratories in technical and scientific institutions both in this country and abroad, as well as in the various State highway commissions.

\section{PHYSICAL PROPERTIES OF ROAD-BUILDING ROCK.}

The suitability of rock for use in highway construction is largely determined in the laboratory by tests of certain physical properties which have a direct bearing upon the behavior of the rock under service conditions. In the case of rock intended for use in waterbound macadam construction, experience has shown that the qualities most essential to success are those of hardness, toughness, and binding power. These properties may be briefly defined as follows: 
Hardness is the property a rock should possess in order to successfully resist the abrasive action of traffic, especially iron-tired vehicles, which tend to grind to dust the individual fragments of rock forming the wearing course of a macadam road.

Toughness is the property a rock should possess to successfully resist fracture under the impact of traffic.

Binding power, or cementing value, as it is more frequently called, is the ability which the dust of a rock should possess or develop by contact with water, so as to bind or cement the larger rock fragments together and prevent their displacement under the shearing action of traffic. This property is especially valuable in water-bound macadam construction, since it is depended upon to maintain the integrity of the wearing course as the road surface is worn off by traffic.

\section{PHYSICAL TESTS OF ROAD MATERIALS.}

A description of the various tests employed to determine to what extent a rock possesses the qualities outlined above, in ad-

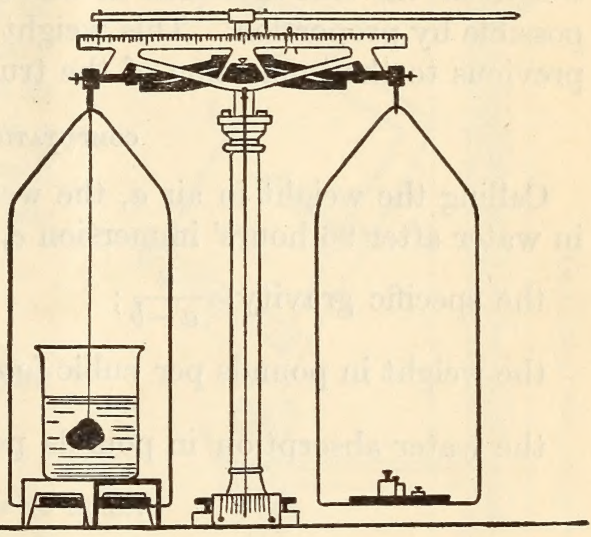

FIG. 1.-Displacement method of determining specific gravity.

dition to certain other properties of interest to highway engineers, is given in the following pages.

SPECIFIC GRAVITY-WEIGHT PER CUBIC FOOT-WATER ABSORPTION.

OBJECT.

To determine the weight of a solid cubic foot of the material and the number of pounds of water which will be absorbed by a cubic foot in 96 hours.

EQUIPMENT.

Beam balance weighing accurately to 0.01 gram and provided with suitable means for suspending the material in water while weighing. (See fig. 1.)

Drying oven.

Desiccator and calcium chloride.

Thermometer.

METHOD.

A fragment of the rock weighing approximately 10 grams and representing as nearly as possible an average of the entire sample is dried for several hours to constant weight in a hot-air bath, cooled 
in a desiccator, weighed in air, weighed in water at $25^{\circ} \mathrm{C}$., immersed in water for 96 hours, and again weighed in water. The specimen should be suspended by means of a thin silk thread from the hook on one of the beam supports about $1 \frac{1}{2}$ inches above the pan when weighing. When weighed immersed in water, the small amount of water absorbed by the thread is neglected. It is essential that the first weight in water be obtained as quickly as possible in order to secure the correct specific gravity of the material. This is especially true of very porous rock. In practice it is customary to do this by first obtaining the approximate weight of a trial specimen, both in air and in water, and of the true test specimen in air. The correct weight of the true specimen in water is next calculated as nearly as possible by proportion. This weight is then placed on the scale pan previous to the immersion of the true specimen in water.

\section{COMPUTATIONS.}

Calling the weight in air $a$, the weight in water $b$, and the weight in water after 96 hours' immersion $c$,

the specific gravity $=\frac{a}{a-b}$;

the weight in pounds per cubic foot then $=\frac{a}{a-b} \times 62.37$ pounds;

the water absorption in pounds per cubic foot $=\frac{c-b}{a-b} \times 62.37$.

VALUE OF TESTS.

The weight per cubic foot is of value in estimating the weight of any given volume, as a cubic yard or carload, of the crushed stone. Thus, assuming 50 per cent voids in the crushed material,

the weight in pounds per cubic yard loose approximately= $\frac{\text { Wt. per solid cu. ft. }}{2} \times 27$.

The absorption test is of value in judging the probable lasting qualities of the rock under the action of frost, since the presence of frost in the stone is likely to promote weakness or even disintegration. It may also be of value in estimating the probable error due to absorption in the weight of a quantity of stone exposed for some time to the weather.

\section{DEVAL ABRASION TEST.}

OBJECT.

To determine the per cent of wear and the French coefficient of wear.

Deval abrasion machine.

EQUIPMENT.

This machine (see fig. 2) consists essentially of the pulley $A$, or worm gear and motor as at present used, driving the shaft $B B$ upon which are mounted the four cast-iron cylinders $C C C C$ in such a way 
that the axes of the cylinders are inclined at an angle of $30^{\circ}$ with the axis of rotation. These cylinders are $20 \mathrm{~cm}$. in diameter and $34 \mathrm{~cm}$. in depth inside. The shaft is set in the three bearings $D D D$ and carries at one end a revolution counter which is not shown in the cut.

Balance weighing to 5 kilograms and sensitive to 0.5 gram.

This balance should preferably be equipped with a supplementary scale pan, measuring 10 inches in diameter and 2 inches high, and a suitable counterweight. This will make it possible to weigh the entire sample in one operation.

50 -pound anvil.

Stone hammers.

Several 3-quart enameled iron pans.

Sieve.

The sieve should preferably be brass rimmed and reinforced in order to withstand heavy usage, about 16 inches in diameter, with square mesh of one-sixteenth (0.0625) inch clear opening.

Drying oven.

\section{METHOD.}

The material is broken into pieces as nearly of the same size and shape as practicable, so that approximately 50 pieces shall weigh, after thorough drying, to within 1 gram of 5,000 grams. In no case should the number of pieces exceed 60 or be less than 40. Care should be taken to use only freshly broken fragments, as pieces with rounded edges greatly affect the results. Although the size of the individual pieces composing a sample varies theoretically

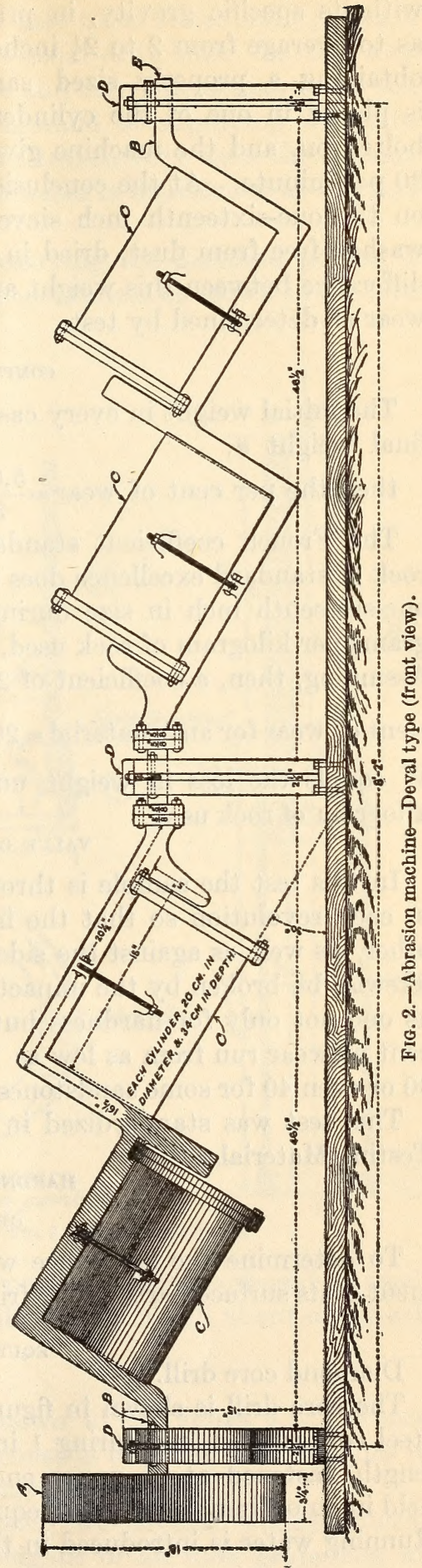


with its specific gravity, in practice the pieces may be so broken as to average from 2 to $2 \frac{1}{2}$ inches in diameter with the assurance of obtaining a properly sized sample. After weighing, the sample is placed in one of the cylinders of the Deval machine, the cover bolted on, and the machine given 10,000 revolutions at the rate of 30 per minute. At the conclusion of the test the sample is screened on the one-sixteenth inch sieve, the material retained thoroughly washed free from dust, dried in the oven, and again weighed. The difference between this weight and that first obtained represents the wear as determined by test.

\section{COMPUTATIONS.}

The initial weight in every case being 5,000 grams, and calling the final weight $a$,

then the per cent of wear $=\frac{5,000-a}{5,000} \times 100$.

The French coefficient standard is based on the theory that a rock of standard excellence does not lose more than 100 grams under one-sixteenth inch in size during a test. This is equivalent to 20 grams per kilogram of rock used, or 2 per cent of the original weight. Assuming, then, a coefficient of 20 for such a rock, the French coefficient of wear for any material $=20 \times \frac{20}{\mathrm{~W}}=\frac{400}{\mathrm{~W}}=\frac{40}{\text { per cent of wear }}$ where $\mathrm{W}$ equals the loss in weight under one-sixteenth inch in size per kilogram of rock used.

VALUE OF THE TEST.

In this test the sample is thrown the length of the cylinder twice in each revolution so that the individual stones grind against each other, as well as against the sides of the cylinders. The rock may likewise be broken by the impact, so that the test may be considered as one not only for hardness but for toughness. Values of the per cent of wear run from as low as 1 in certain rare cases to as high as 30 or even 40 for some sandstones and limestones.

This test was standardized in 1908 by the American Society for Testing Materials.

\section{HARDNESS TEST.}

OBJECT.

To determine the resistance which a rock offers to the displacement of its surface particles by friction.

Diamond core drill.

EQUIPMENT.

The core drill is shown in figure 3 , and consists essentially of the steel core tube $A$, measuring 1 inch inside diameter and 4 inches in length, fastened at its upper end to the hollow shank $B$. This is held in an ordinary drill press, equipped with a special hollow spindle. Running water is introduced in the upper end of the spindle from a 
one-fourth-inch pipe, while the drill is held in its lower end by means of a headless set screw instead of the usual drift hole. In this way water may be carried in a very simple and convenient manner to the inside of the revolving drill. This method of supplying water to the drill has proved simpler and more satisfactory than the scheme described in Bulletin 44, in which the water is introduced at the side through a stationary brass ring.

The Tobin bronze drill crown $C$, carrying the diamond points, is soldered to the lower end of the steel core tube $A$ as shown in the cut.

The crown should measure about oneeighth of an inch thick across its lower face, should be about three-sixteenths of an inch thick, and show a slight taper in its outer side, to allow clearance when cutting. Eight or ten holes are drilled in the lower face of the crown, of such size that the diamonds will wedge firmly into them, until nearly flush with the surface.

Black diamonds or carbons.

The diamonds used in the drills and saws should be dense, regular in shape, and should range in size from one-sixteenth of an inch to three thirty-seconds of an

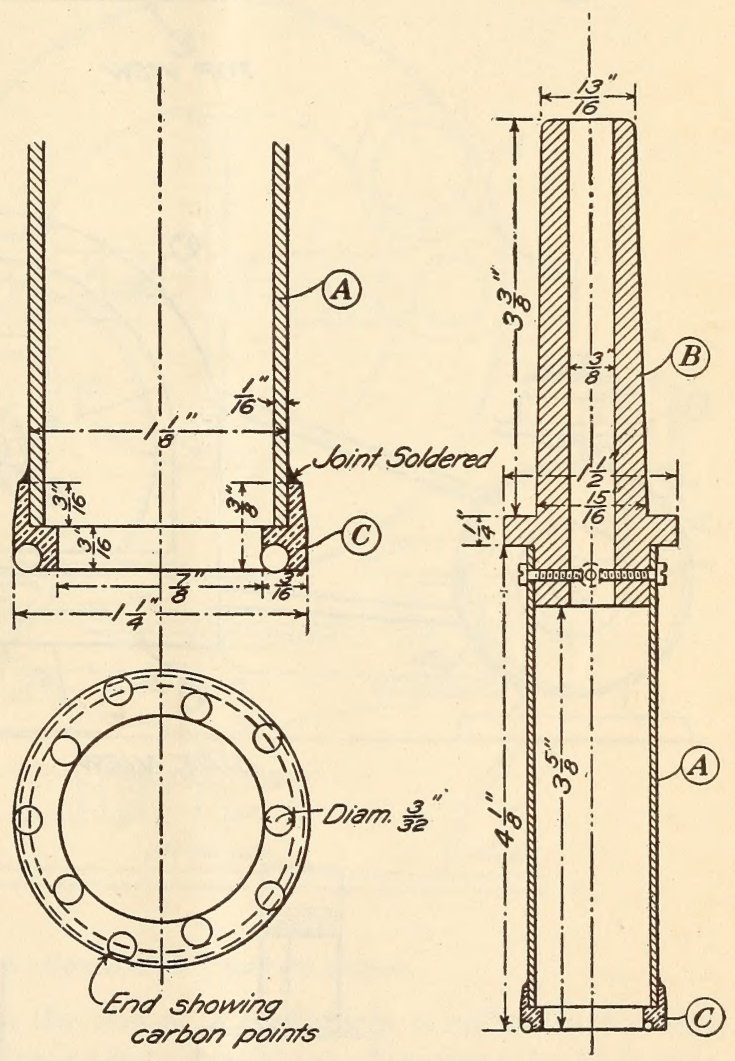

FIG. 3.-Diamond core drill. inch in diameter. No flat, scaly, or porous diamonds should be used. Diamonds suitable for this work will usually weigh about one-tenth of a carat (0.02 gram) each.

Diamond saw.

A cut of the diamond saw is shown at $A$, figure 4. The saw proper is made of Russia iron and consists of a flat disk 8 inches in diameter and 0.03 inch thick. It is made as follows:

The saw is firmly clamped between two circular wooden blocks $7 \frac{3}{4}$ inches in diameter, leaving one-eighth of an inch projecting all 

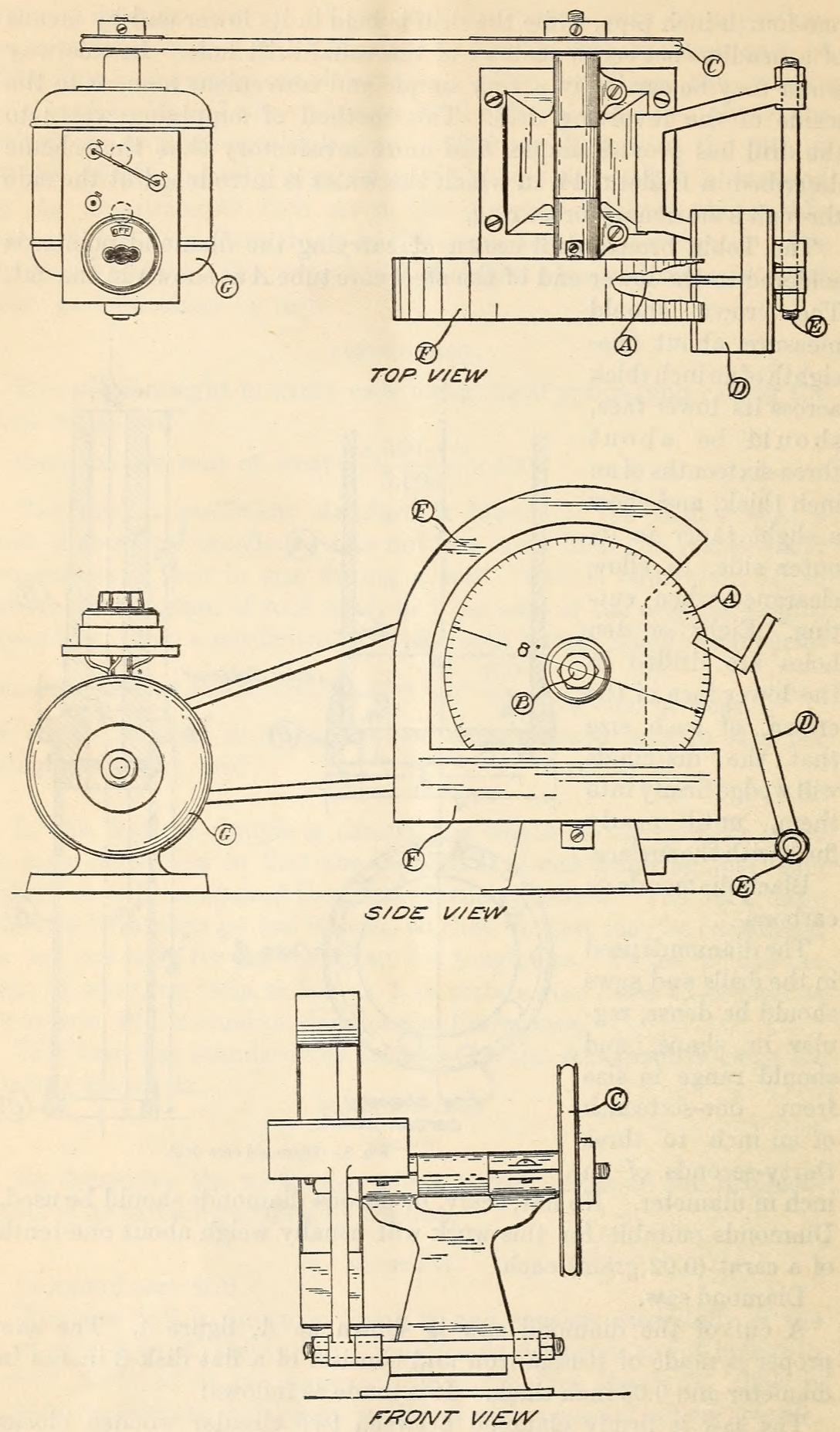

FIG. 4.-Diamond saw. 
around. By means of a small one-fourth-inch steel chisel radial cuts are made in the saw one-eighth of an inch apart and one-eighth of an inch deep. The spaces between the cuts are then slightly opened by bending the projections alternately to the right and left. A mix ture of vaseline and fine diamond fragments is inserted in each cut. All of the cuts are then closed with a pair of pincers and hammered down to the original thickness of the saw, thus driving the diamond dust into the metal. The diamonds are not ground to a powder, but are merely broken up into very fine fragments. A very small amount

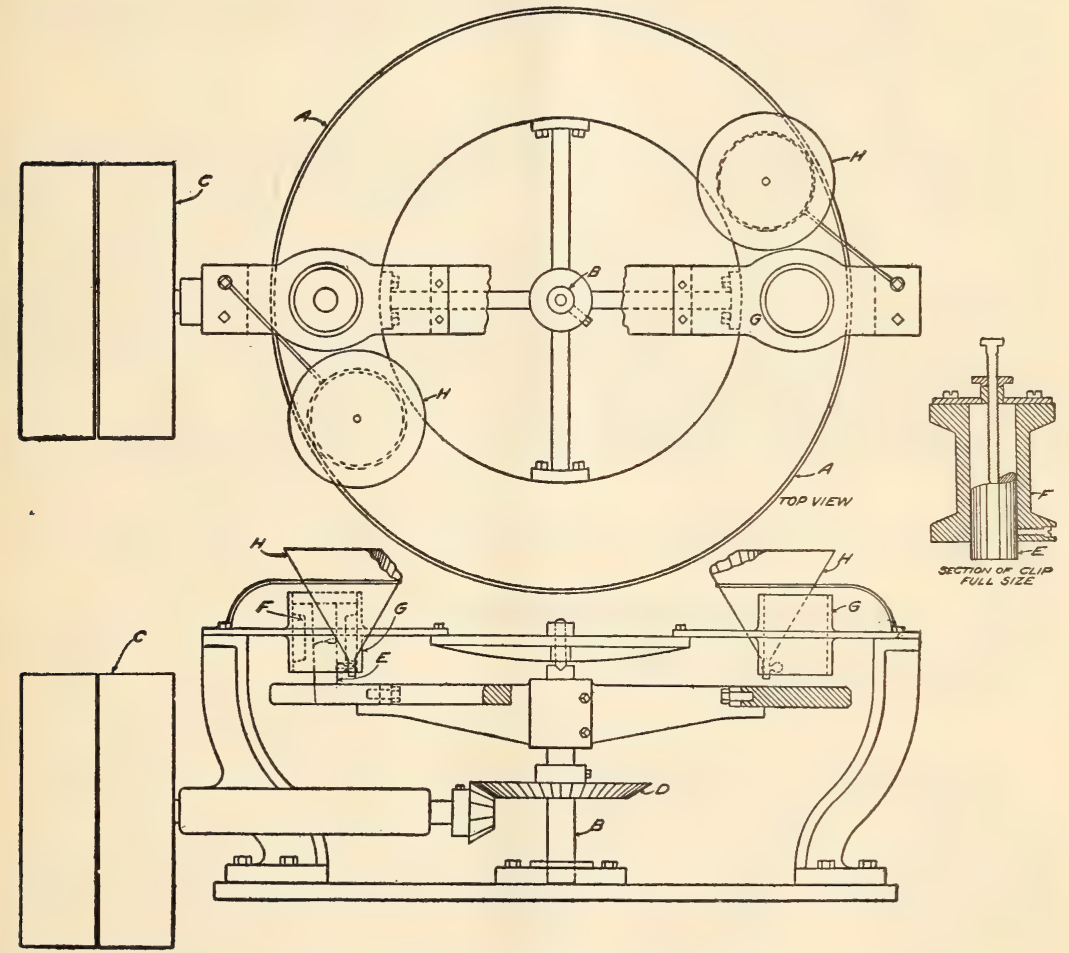

FrG. 5.-Details of Dorry hardness machine.

of the mixture taken on the end of a toothpick is sufficient for each cut. Just enough vaseline is used to enable one to pick up the diamonds.

The saw is mounted on a spindle ( $B$, fig. 4 ) driven by the pulley $(C)$ at 600 revolutions per minute from a motor $(G)$. The specimen to be cut is held in the $\mathrm{V}$ block $(D)$, which is mounted on a swinging arm pivoted as at $(E)$. The lower end of the saw runs continuously in water contained in the galvanized-iron pan $(F F)$.

Dorry hardness machine.

The Dorry machine in use at the present time is a modification of the original French machine, and consists fundamentally of a circular steel disk ( $A$, fig. 5 ), which is revolved in a horizontal plane by means 
of the bevel gear $(D)$, driven by the pulley $(C)$. At $F$ is shown a brass grip for holding the test specimen. The grip carrying the specimen is held in a vertical position over the steel disk by inserting it in the sleeve $(G)$, which is of such size as to form a sliding fit allowing free vertical but no sidewise movement of the grip. The abrasive, crushed quartz is fed onto the disk through the funnel $(H)$, the lower end of which should form an opening one-fourth of an inch in diameter. The sleeve $(G)$ is so placed that the center of the grip, when in position, will be $26 \mathrm{~cm}$. from the center of rotation of the disk. A revolution counter is mounted as at $(B)$. A galvanized-iron hopper, not shown, is fitted under the disk to receive and carry away the used sand.

Crushed quartz sand.

The sand used as the abrasive agent is a crushed quartz, screened to pass a standard sieve having 30 meshes per linear inch and to be retained on a standard sieve having 40 meshes per linear inch. Since it is almost impossible to obtain such a sand commercially, it is customary to specify a sand not more than 5 per cent of which will be retained on a No. 30 sieve and not more than 25 per cent of which will pass a No. 40 sieve. Sand known to the trade as No. $2 \frac{1}{2}$ quartz will usually fulfill these requirements.

Standard sieve 16 inches in diameter, with 30 meshes per linear inch.

Standard sieve 16 inches in diameter, with 40 meshes per linear inch.

Balance, same as used in abrasion test.

Several small metal washers.

METHOD.

A core $25 \mathrm{~mm}$. in diameter and about $10 \mathrm{~cm}$. long is cut with the diamond drill from the specimen to be examined. To use the diamond drill properly, so as to avoid undue wear, requires great care and considerable experience. It is convenient to mount the specimen under test on the table of the drill press by means of a bag filled with sand, which forms a cushion for the irregular, projecting edges of the rock. Very small specimens may be mounted in plaster of Paris. The core should in every case be drilled perpendicular to the bedding plane of the rock, using the hand feed of the drill press only, with just enough pressure to cut. Should the core be not cut entirely through the specimen it may be removed by inserting the end of a small screw driver into the cut and using it as a lever to break the core away from the bottom. After thoroughly drying, the specimen is inserted in the brass grip of the Dorry machine, leaving about 1 inch projecting from the lower end. The grip is then inserted in the sleeve so that the lower end of the specimen rests on the steel disk. The funnel is filled with sand and the machine run until the lower end of the specimen has been worn down to the plane of the disk. The 
grip carrying the specimen is then removed, brushed free from dust, and accurately weighed. By means of the small metal washers, any one or more of which may be slipped over the projecting rod of the grip, the initial weight should be adjusted to exactly 1,250 grams. The grip is then replaced in the same position as before and the machine given 1,000 revolutions at the rate of 30 per minute, after which it is again weighed. The test should be repeated with the specimens reversed, in order to obtain the average hardness of the two ends.

The one-fourth inch opening in the funnel of the hardness machine will allow 18.5 pounds of sand to pass through during a test.

COMPUTATIONS.

Calling the initial weight of grip plus specimen $a$ and the final weight after 1,000 revolutions $b$,

the coefficient of hardness $=20-\frac{(a-b)}{3}$.

The coefficient 20 was chosen as the standard of comparison to give about the same range of values as those obtained by the Deval abrasion test. The loss in weight is divided by 3 in order to avoid negative coefficients, since it was found that a specimen might lose as high as 60 grams in a single test.

VALUE OF TEST.

The test is of value in determining the resistance of a rock to the grinding action of traffic. The coefficient of hardness for various types of rock will run from 19.7 for the hardest varieties of quartzite to 0 for very soft limestones and sandstones.

TOUGHNESS TEST.

OBJECT.

To determine the resistance which the material offers to fracture due to impact.

EQUIPMENT.

Diamond core drill (same as used in hardness test).

Diamond saw (same as used in hardness test).

Grinding lap.

The grinding lap used for preparing specimens for the toughness test is shown in figure 6 . It is 9 inches in diameter and is driven by means of a small electric motor at a speed of 400 revolutions per minute. Finely powdered carborundum is used as an abrasive agent.

No. 120 carborundum.

Page impact machine.

In the Page impact machine (fig. 7), a 2-kilogram hammer ( $M$ ) is guided by two vertical rods $(J)$. The upper end of the hammer 
has a small cone set in it, which fits snugly into a concentric electromagnet, and this is attached to the lower side of a crosshead ( $M$ )

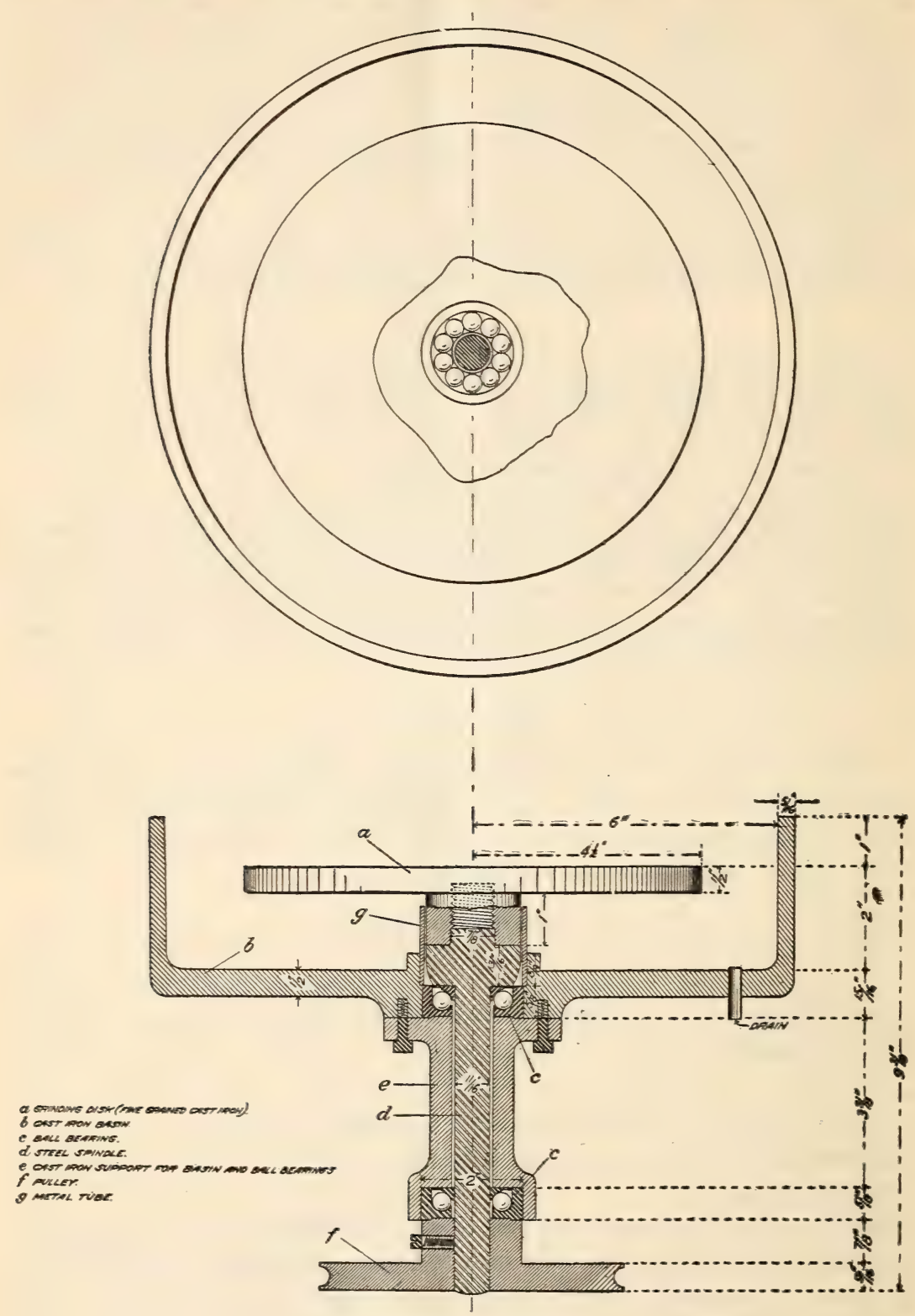

FIG. 6.-Details of grinding lap.

which slides freely on the guide rod $(J)$. This crosshead is provided with a slot in its rear side through which a sprocket chain $(S)$ passes, and this sprocket chain is supported on the sprocket wheels, which 

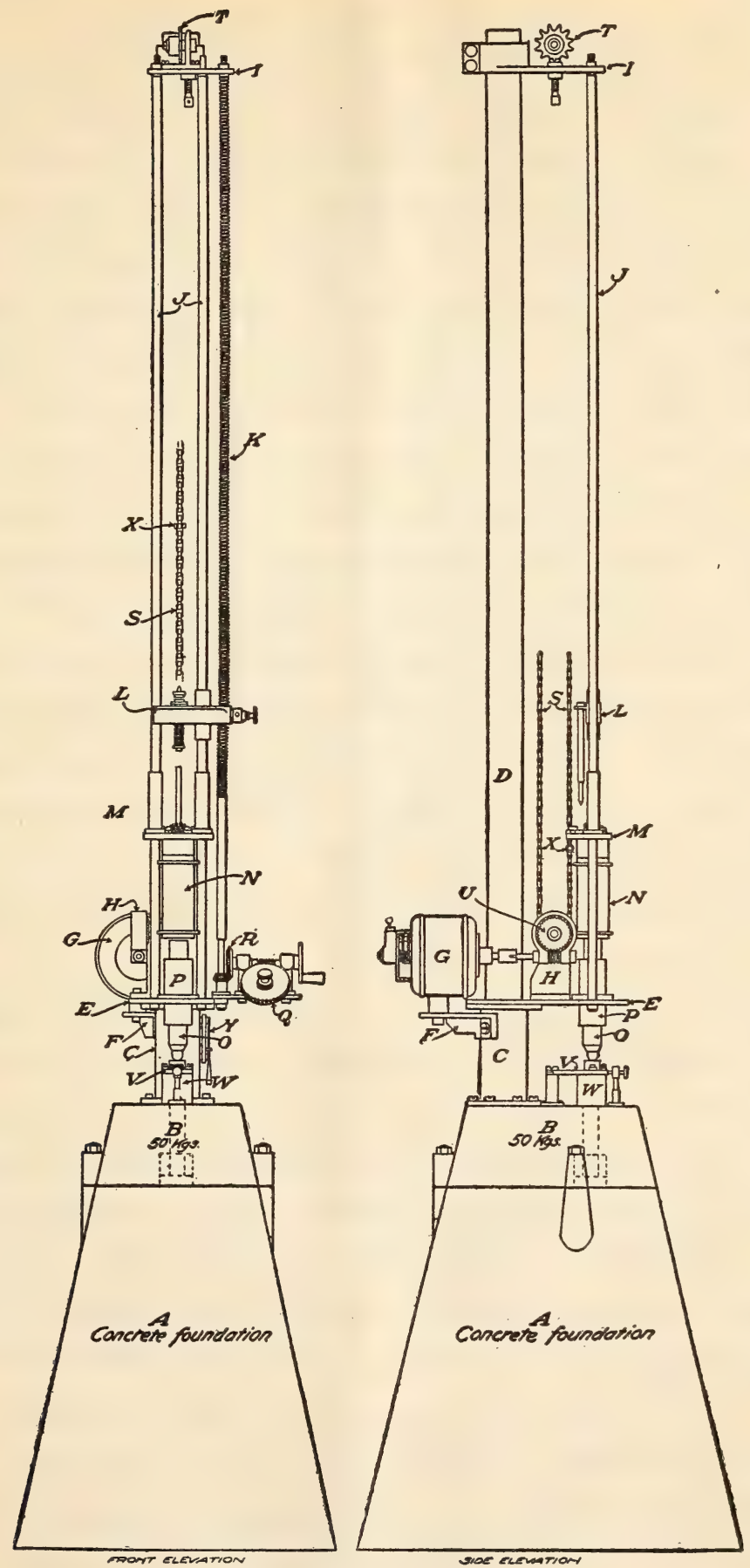

FIG. 7.-Details of Page impact testing machine. 
are attached to castings at the top $(I)$ near the base $(H)$ of the machine. The lower sprocket wheel is directly connected by a worm gear to an electric motor $(G)$. The sprocket chain is provided with four small lugs $(X)$, which, when the chain is being driven by the motor, engage a spring bolt attachment which projects inward on either side of the slot on the crosshead $(M)$. This raises the crosshead until tripped by a rod projecting downward from an upper crosshead $(L)$. When this takes place the crosshead $(M)$ which holds the electromagnet falls until it comes in contact with the hammer $(N)$. The electromagnet is supplied with current from the circuit in series with an ordinary electric lamp which not only serves to cut the voltage in the line but acts as a pilot lamp as well. This current is conveyed through two small conducting rods running parallel to the guide rods, both of which are insulated from the rest of the machine. The current passes from one of these conductor rods through a small carbon brush to a make-and-break attachment on the upper crosshead $(L)$, thence down one of the guide rods, through the electromagnet, and back to the other conductor rod.

When the crosshead ( $M$ ) is raised by the lugs on the sprocket chain and the current turned on the magnet the hammer is lifted until the crosshead $(M)$ comes in contact with the make-and-break on the crosshead $(L)$ and thus releases the hammer, which falls, striking a plunger $(O)$. The plunger is made of armor-piercing steel, with the maximum temper at its lower end, which is spherical in shape. The upper surface of the test piece, which rests on a counter anvil (W) of hard steel, is in direct contact with and tangent to the spherical end of the plunger at its center point.

It will be observed that the blow as delivered through a sphericalend plunger approximates as nearly as practicable the blows of traffic. Besides this it has the further advantage of not requiring great exactness in getting the two bearing surfaces of the test piece parallel, as the entire load is applied at one point of the upper surface.

The upper crosshead $(L)$ is raised through any desired height by means of the long revolving screw $(K)$, which is geared at its lower end to a dial $(Q)$, on which the height of the make-and-break attachment, and therefore the height of the hammer drop, may be read directly. By means of the revolving dial and screw the height of the crosshead may be adjusted, by very close approximation, to within 1 millimeter.

In order to prevent the crosshead $(M)$ which holds the electromagnet from striking too hard a blow on the hammer when falling, a dashpot was first used, but it has been found that a few drops of cylinder oil on the lower end of the guide rods completely eliminated this difficulty. 
METHOD.

A core of the rock which is to be tested is first drilled, as described under the hardness test. In many cases the core which has already been subjected to the hardness test may be used. A cylinder a littlo over 25 millimeters long is next cut from the rock core by means of the diamond saw. The ends are then ground plane on the grinding lap, making the length of the specimen when completed exactly 25 millimeters. Although it is not necessary that the two ends of the specimen be exactly parallel, one surface at least should be as nearly perpendicular to the axis of the cylinder as it is possible to make it. After drying, the specimen is placed on the anvil $(W)$ of the Page impact machine, taking extreme care that when in position the specimen rests with a perfect bearing on the anvil and that the spherical end of the plunger touches the specimen exactly in the center of its upper surface. The small thumbscrew used for separating the clips which hold the specimen in place should be so adjusted that the clips hold the specimen firmly without any undue pressure on the spring. Attention to these details is very important if accurate results are to be obtained. When the specimen is in position the current is turned on the magnet and the upper crosshead is lowered until the rod projecting from it just comes in contact with the rod projecting up from the lower crosshead $(M)$. This occurs at the instant the pilot lamp, in series with the magnet circuit, flashes out. The dial $(Q)$ is then adjusted to $(O)$, the upper crosshead raised 1 centimeter, and the motor started. After each blow the fall of the hammer is increased 1 centimeter until failure of the test piece occurs.

COMPUTATIONS.

The height in centimeters of the blow at failure is recorded as the toughness of the material. The average of two determinations is taken.

VALUE OF TEST.

This test is useful in determining the comparative resistance of rock to the impact of traffic produced by the action of horses' hoofs, etc., on the stones forming the wearing course of a macadam road. Toughness in rock varies through a wide range of values from as low as 2 or 3 in the case of some limestones and sandstones to as high as 60 in rare instances.

This test was standardized in 1908 by the American Society for Testing Materials.

\section{CEMENTING VALUE TEST.}

OBJECT.

To determine the ability which the rock powder, when wet, possesses of binding the larger fragments together. 
Small jaw crusher.

EQUIPMENT.

Balance (same as used in abrasion test).

100 c. c. graduate.

Several 1-pint jars, with metal screw caps.

Ball mill.

The ball mill shown in figure $\mathrm{S}$ consists essentially of the cast-iron casing $(A B)$, split into the two unequal segments $(A$ and $B)$. It revolves in a vertical plane on the shaft $(C C)$ bearing in the pillow blocks $(D D)$ and driven by the pulley $(E)$. The steel shot used for grinding measure 5 inches in diameter and weigh 20 pounds each. Two shot are used in each mill.

Briquette-forming machine.

This machine is shown in figure 9 and consists fundamentally of a hydraulic cylinder $(A)$ supporting an iron platform $(B)$ through the piston $\operatorname{rod}(C)$. The cylindrical metal die $(D)$ is provided with a closely fitting plug $(E)$ supported by guide rods $(K K)$. The supply pipe shown in the cut admits water to the cylinder. The lever arm $(G)$ is provided with an adjustable weight $(H)$ consisting of a hollow cylinder partially filled with shot. Details of the metal die are shown in figure 10, in which a small metal stand $\left(A^{\prime}\right)$ shaped in the form of a half circle is used in removing the compressed material.

Small balance weighing to 100 grams and sensitive to 0.1 gram.

Millimeter scale.

Drying oven.

The oven should be equipped with a thermometer and regulating device for maintaining a constant temperature of $100^{\circ} \mathrm{C}$. for several hours.

Desiccator and calcium chloride.

Shellac dissolved in alcohol.

Page impact machine for testing cementing value.

The machine as shown in figure 11 consists essentially of the motor $(A)$ driving the cam shaft $(\mathrm{E})$ by means of a worm gear at the rate of 60 revolutions per minute. The plunger $(H)$, weighing one-half kilogram, is held in position on the briquette $(I)$ by means of two spiral springs, one on each side of the sleeve in which the plunger slides. The lever $(L)$ is pivoted on the plunger through a slot cut in the sleeve. It carries a brass pencil at one end, while the other is provided with means for adjusting the height of the pencil with reference to the drum $(M)$. The hammer $(G)$, weighing 1 kilogram, is raised by the pin $(F)$ which slides upon the face of the cam $(E)$. The pin is provided with a thumbscrew and locknut $(F)$ for adjusting and maintaining its vertical position. The cam $(E)$ is also provided with means for imparting at each revolution a slight motion to the drum $(M)$, so that the drum makes one complete revolution for each 100 blows of the hammer. 


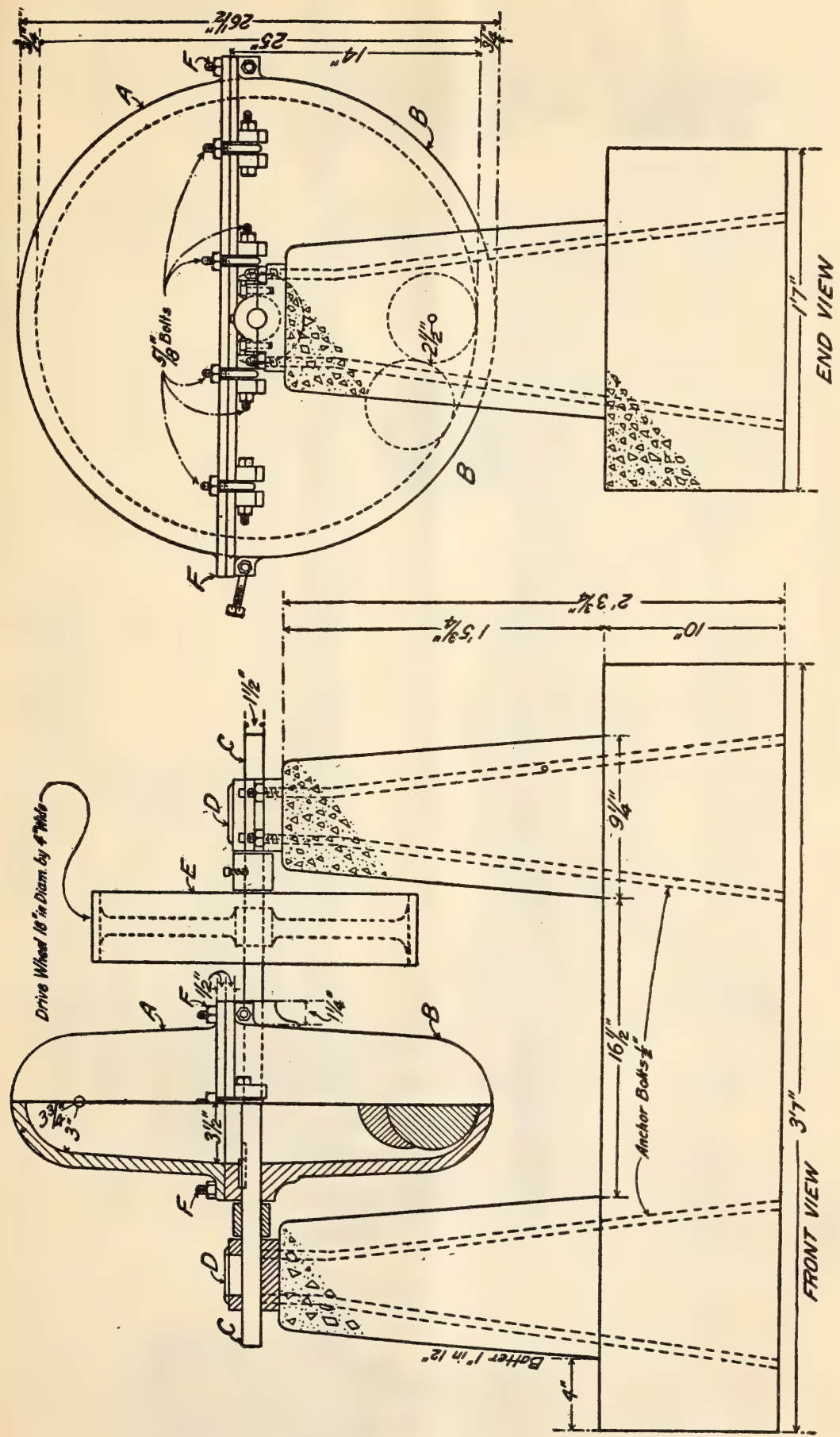


BULLETIN 347, U. S. DEPARTMENT OF AGRICULTURE.
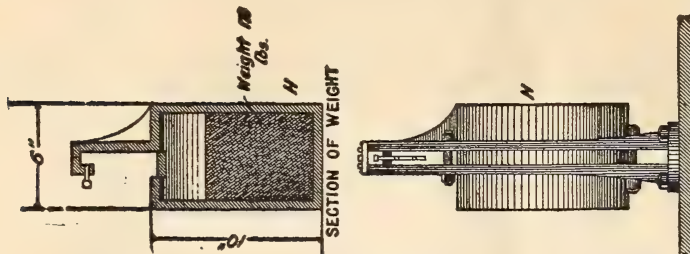

恙
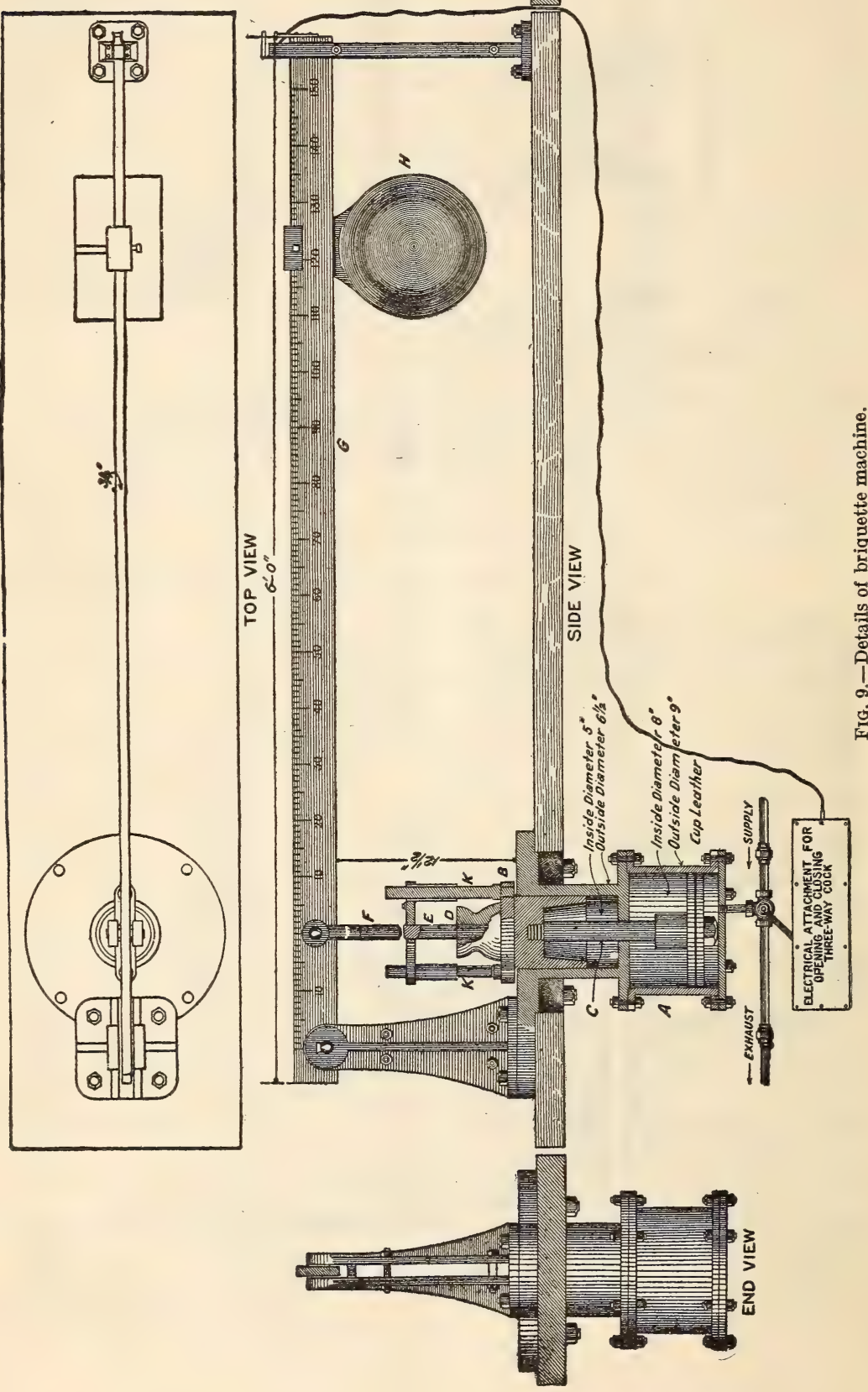
Sensitized paper.

The paper used for recording the number of blows delivered by the hammer of the impact machine measures 8 by $2 \frac{3}{4}$ inches in size and is sensitized on one side to take the impression of a brass point.

\section{METHOD.}

A 500-gram sample of the material to be tested is crushed to pea size and placed in the ball mill together with 18 per cent $(90 \mathrm{c.}$ c.) of water. After 5,000 revolutions of the mill, at the rate of 30 per min-
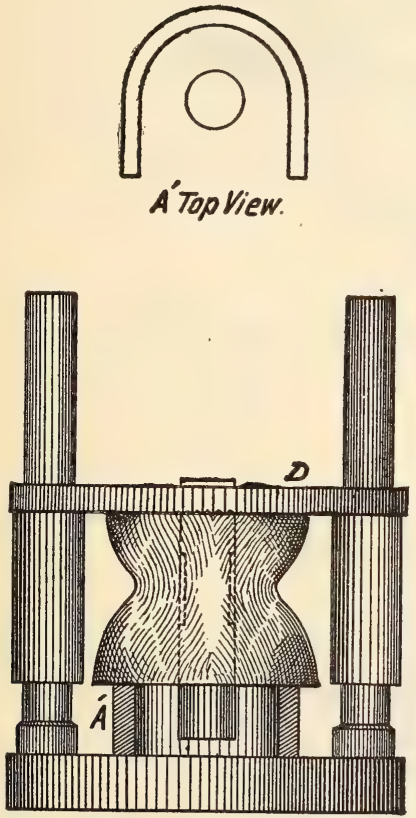

Illustrating method of removing
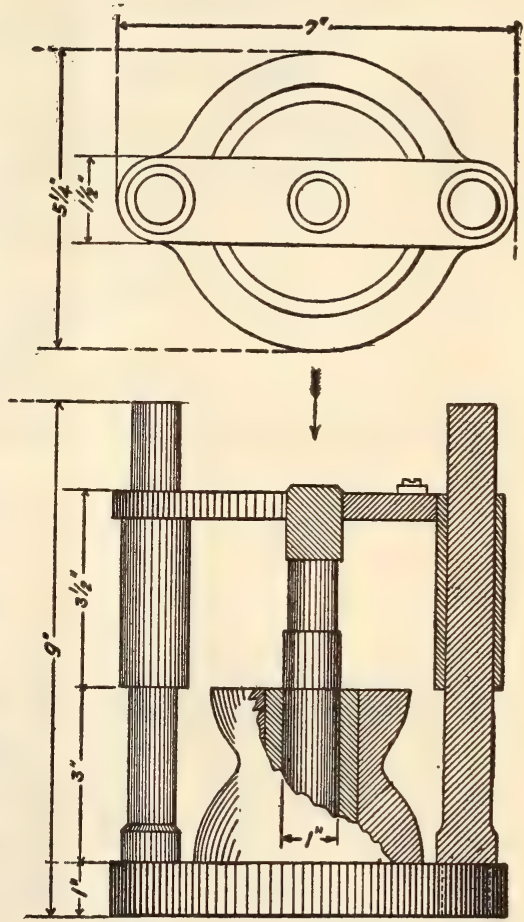

Position of mold before compression.

Fig. 10.-Details of briquette mold.

ute, the resulting dough is removed and molded into briquettes 25 $\mathrm{mm}$. in diameter and $25 \mathrm{~mm}$. high. The dough should never be allowed to stand in the open air after grinding and previous to molding, but should be tightly sealed in a fruit jar. Even when sealed, however, the dough should not be allowed to stand more than two or three hours before molding into briquettes. In order to obtain briquettes of the proper height, a trial specimen should be made as follows: 28 grams of the material is weighed and placed in the die, the plunger inserted, and the whole placed upon the platform of the briquetting machine. Water is admitted to the cylinder until the 
pressure is just sufficient to raise the lever arm. This will take about 30 seconds. The weight on the lever arm should be so adjusted that there will be a maximum pressure on the briquette of 132 kilograms

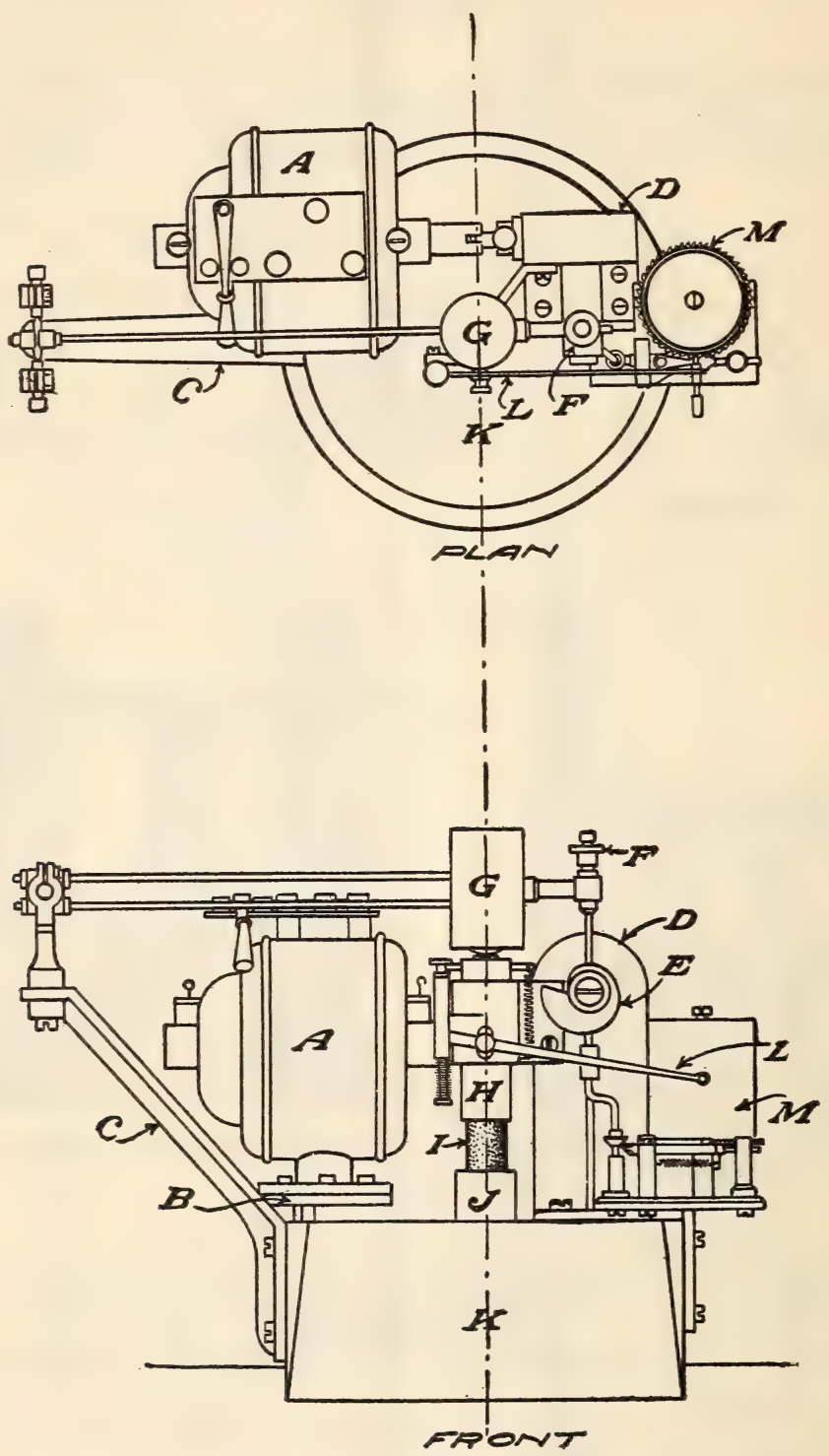

FIG. 11.-Details of Page impact machine for testing cementing value.

per square centimeter. At the moment the lever arm is raised the pressure should be released. The briquette is then removed as shown in figure 10 and its height carefully measured. Add or subtract 1 
gram from the material forming the next briquette for each millimeter variation from 25 in the height of the trial specimen. Six briquettes $25 \mathrm{~mm}$. high should be made from each sample. They are allowed to dry in the air at ordinary room temperature for 20 hours after making, and are then dried at a temperature of $100^{\circ} \mathrm{C}$. for four hours, cooled for 20 minutes in a desiccator, and immediately tested. Briquettes should not be allowed to stand in the open air while waiting to be tested, but should be kept in the desiccator. In making the test the briquette is held in position on the anvil of the testing machine by means of a drop of thick shellac, extreme care being taken to see that there is perfect contact between the upper surface of the briquette and the plunger, as well as between its lower surface and the anvil. There will ordinarily be no difficulty in securing this result. In certain highly argillaceous materials, however, the shrinkage caused by drying out sometimes warps the briquette so that its two ends are not parallel. In such a case a perfect bearing can only be secured by very carefully grinding the end of the bri-

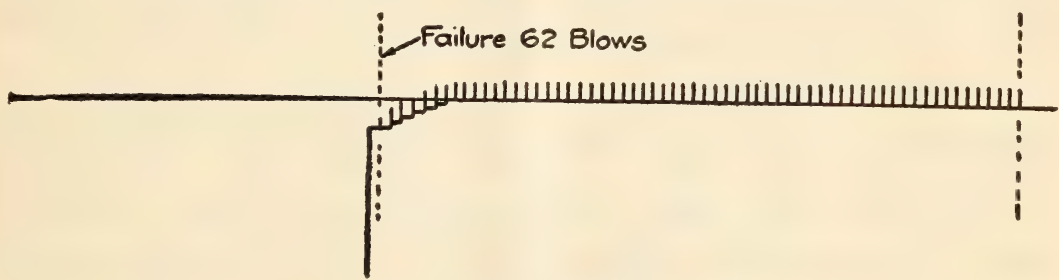

Fig. 12.-Record of cementing-value test.

quette on a piece of fine emery cloth until a satisfactory bearing is obtained. With the briquette in position, the plunger resting on it, and the cam in the position shown in figure 11, the end of the pin $(F)$ is brought into contact with the surface of the cam and the locknut tightened. This will give an effective drop of $1 \mathrm{~cm}$. to the hammer. The brass pencil is so adjusted that on revolving the drum a horizontal line will be traced on the sensitized paper which is wrapped tightly around it and held in place by a rubber band. On starting the motor, each blow of the hammer will then be recorded in a short vertical line above the base line. The number of blows required to destroy the resilience of the briquette will equal the number of vertical lines showing on the record above the base lines. A typical record is shown in figure 12 . In counting the number of vertical lines showing on the record, no attention should be paid to the fact that the short horizontal lines gradually drop below the original base line. Each vertical line which shows above the corresponding horizontal base line on its right should be counted as part of the record. The typical record shown in figure 12 brings out this point clearly. 


\title{
COMPUTATIONG.
}

The number of blows required to destroy the specimen is called its cementing value. An average of five determinations is taken.

\section{VALUE OF THE TEST.}

On account of the great number of variables entering into this test, some of which are very difficult to control, concordant results are not always obtainable. Also, certain types of rock, particularly some varieties of sandstone, give results that appear to be at variance with those obtained in actual practice. With this exception, however, the test will, if properly carried out, give a very good preliminary idea of the binding power of the material under examination. Results of this test vary enormously, running from 0 for pure quartz to as high as several thousand blows in the case of high-binding clays.

\section{COMPRESSION TEST.}

This test is not ordinarily made upon road-building rock. Since, however, it is included in certain specifications for rock used as paving block, it is made when requested in the following manner:

A cylindrical test specimen 2 inches in diameter and 2 inches high is prepared by the same method as previously described under the toughness test, except that a 2-inch core drill is used. Both ends of the specimen which have been properly faced are then bedded in plaster of Paris, and the cylinder crushed in a 200,000-pound universal testing machine. A small 2-inch spherical bearing block is placed between the moving head of the machine and upper surface of the specimen. The average of at least two determinations are reported as the crushing strength calculated in pounds per square inch.

\section{APPENDIX A.}

Samples of road-building rock are tested free of charge by the Office of Public Roads and Rural Engineering for any citizen of the United States provided the samples are submitted strictly in accordance with full printed instructions, which are sent on request. The following forms are used by this laboratory in connection with the work of rock testing:

Form 6-Rev.

\author{
United States Department of Agriculture, \\ Office of Public Roads and Rural Engineering, \\ Washington, D. C.
}

INSTRUCTIONS FOR SELECTING AND SHIPPING SAMPLES.

In order to have road materials tested in the laboratory of the Office of Public Roads and Rural Engineering the instructions below must be carefully followed:

1. All samples shall be selected to represent as nearly as possible an average of the material. 
2. A sample of rock for laboratory tests shall consist of stones which will pass through a 3-inch but not through a $1 \frac{1}{2}$-inch ring-excepting one piece, which should measure approximately 4 by 6 inches on one face and be about 3 inches thick. The whole sample shall weigh not less than 25 pounds. It is desired that samples of rock be shipped in strong burlap bags.

3. A sample of gravel shall weigh not less than 25 pounds. Such samples must be shipped in boxes or bags sufficiently tight to prevent the finer material from sifting out. In selecting samples of gravel great care should be exercised in order to obtain material that is an average of the run of pit.

4. Samples of sand, clay, or marl must weigh at least 10 pounds and should be shipped in strong cloth bags or tight boxes.

5. A sample of cement should weigh at least 10 pounds and be shipped in a strong, tight cloth bag.

6. A blank form and addressed tag envelope will be supplied by the Office for each sample. The blank form must be filled out and placed in the tag envelope, which must be securely fastened to the bag and used as the address for the sample. It is essential that the blank forms be filled out with the utmost care, as they are filed as records of the samples. A form, properly filled out, must be attached to each sample.

7. The Office desires to keep a record of the actual wear on roads built of the materials tested. If the material which this sample represents has been or is about to be used on roads, this Office desires to be informed of the addresses of those in charge of the construction and maintenance of such roads.

8. Samples may be shipped, freight, express, or parcel post, and must be fully prepaid.

9. The Office makes no charge for tests.

\section{Logan Waller Page, Director.}

Form 5.

\section{United States Department of Agriculture, Office of Public Roads and Rural Engineering, WASHINGTON, D. C.}

The sample of road material described below is a

(Stone, sand, gravel, etc.)

From the property of .

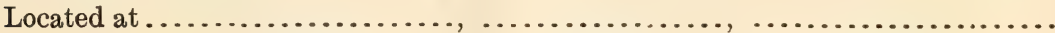

(Town.) (County.) (State.)

Submitted by

(Town.)

(County.)

(State.)

At request of.

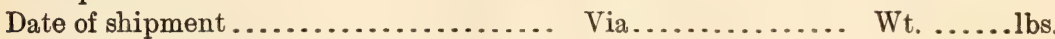

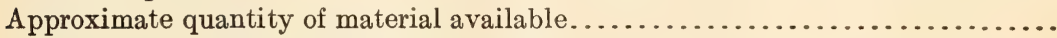

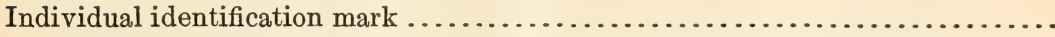

It is desired that this material be tested to determine its suitability for use as follows:

Note.-In order to have the proper tests made, it is essential that the above statement be as complete as possible.

Has material been used on roads? If so, where, in what type, and with what results?

Do not write below this line.

LABORATORY RECORD

Date received

Serial No.

Condition of sample.

Receipt acknowledged 
24 BULLETIN 347, U. S. DEPARTMENT OF AGRICULTURE.

Form 16.

United States Department of Agriculture, Office of Public Roads and Rural Engineering, Washington, D. C.

\section{DEAR SIR:}

Your sample of No.

from

has been received and will be tested in the order of its arrival.

Very truly yours,

Director.

Remarks. 
PHYSICAL PROPERTIES OF ROAD-BUILDING ROCK.

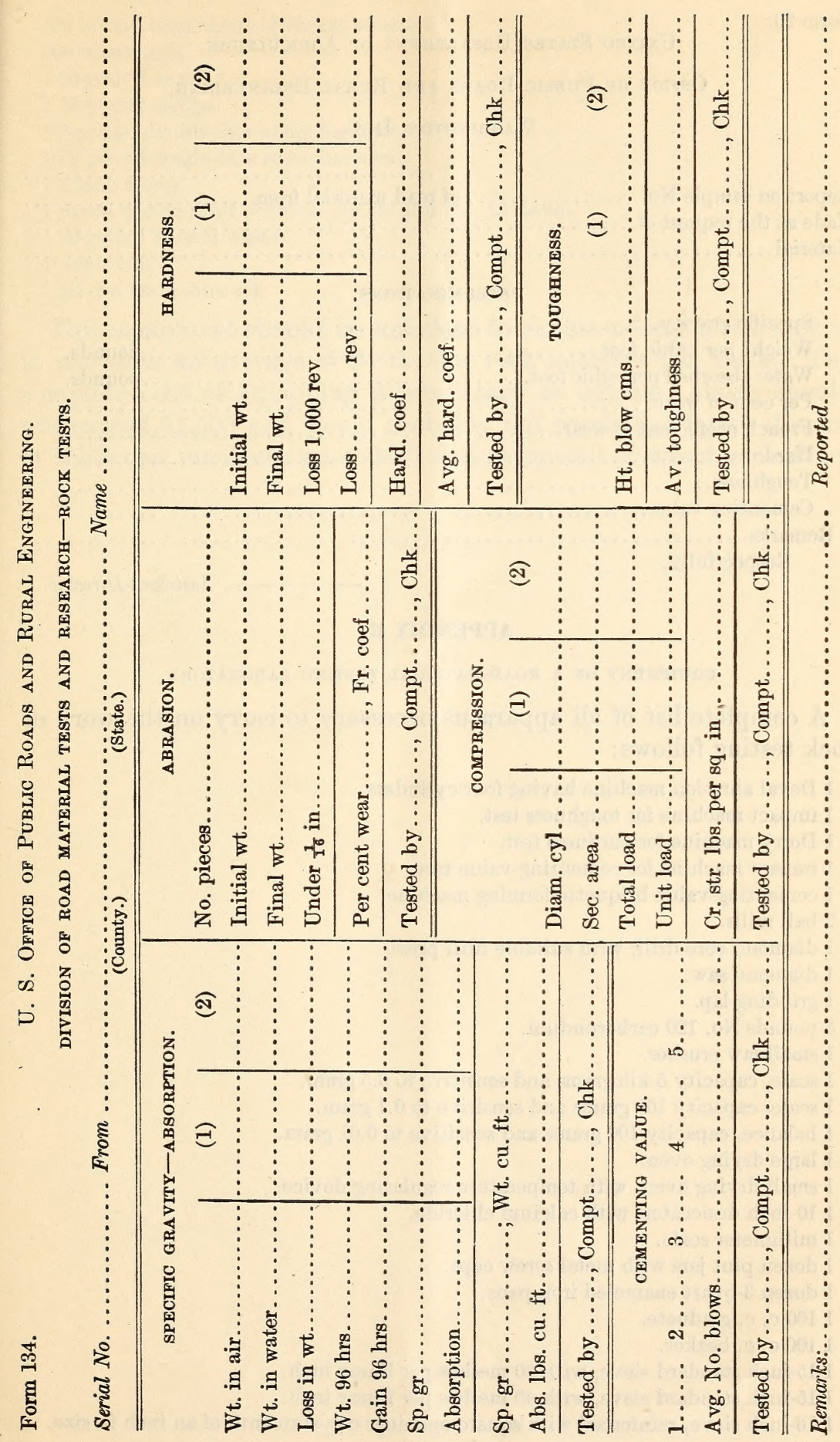


Form 20.

United States Department of Agriculture,

Office of Public Roads and Rural Exgineering,

Washington, D. C.

Report on sample No.

of road material from

Made at the request of

Material.

DETERMINATIONS.

Specific gravity

Weight per cubic foot............

Water absorbed per cubic foot.........

Per cent of wear.................

French coefficient of wear...........

Hardness.

Toughness.

Cementing value.

Remarks...

Respectfully,

pounds.

pounds.

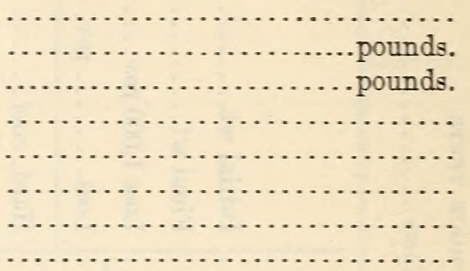

Assistant Director.

\section{APPENDIX B.}

EQUIPMENT OF A ROAD-MATERIAL TESTING LABORATORY.

A complete list of all apparatus necessary to carry on the work of rock testing follows:

1 Deval abrasion machine having four cylinders.

1 impact machine for toughness test.

1 Dorry machine for hardness test.

1 impact machine for cementing-value test.

1 cementing-value briquette-forming machine.

2 ball mills.

1 diamond core drill, with suitable drill press.

1 diamond saw.

1 grinding lap.

5 pounds No. 120 carborundum.

1 small jaw crusher.

1 scale, capacity 5 kilograms and sensitive to 0.5 gram.

1 scale, capacity 100 grams and sensitive to 0.1 gram.

1 balance, capacity 100 grams and sensitive to 0.01 gram.

1 large drying oven.

1 small drying oven, with temperature-regulating device.

1 10-inch desiccator, with calcium chloride.

1 millimeter scale.

1 dozen pint jars with metal screw caps.

1 dozen 3-quart enameled iron pans.

1100 c. c. graduate.

1100 c. c. beaker.

1 15-inch standard sieve, with 30 meshes per linear inch.

1 15-inch standard sieve, with 40 meshes per linear inch.

1 16-inch sieve, reinforced with square openings one-sixteenth of an inch in size. 
100 burlap bags about 17 inches square.

500 blank tags.

150 -pound anvil,

1 10-pound sledge.

13 -pound double-face stone hammer.

$11 \frac{1}{2}$-pound single-face stone hammer.

16 -inch scoop.

1 barrel quartz sand between No. 30 and No. 40 sieves.

150 -pound bale of waste.

1 waste can.

1 oil can and motor oil.

This equipment should be sufficient to enable a force of three men to maintain an average of 24 routine rock analyses per week. The complete cost of equipping a laboratory as outlined above should not exceed $\$ 1,500$ and would probably not reach this figure if some of the larger machines were shaft driven instead of direct connected. 


\section{PUBLICATIONS OF THE UNITED STATES DEPARTMENT OF AGRICULTURE RELATING TO ROADS AND ROAD-BUILDING MATERIALS.}

\section{AVAILABLE FOR FREE DISTRIBUTION.}

Repair and Maintenance of Highways. (Roads Bulletin 48.)

Highway Bonds. (Department Bulletin 136.)

Road Models. (Department Bulletin 220.)

Portland Cement Concrete Pavements for Country Roads. (Department Bulletin 249.)

Sand-clay and Burnt-clay Roads. (Farmers' Bulletin 311.)

Macadam Roads. (Farmers' Bulletin 338.)

Benefits of Improved Roads. (Farmers' Bulletin 505.)

The Road Drag and How it is Used. (Farmers' Bulletin 597.)

Oil-mixed Portland Cement Concrete. (Department Bulletin 230.)

FOR SALE BY THE SUPERINTENDENT OF DOCUMENTS.

The Construction of Macadam Roads. (Roads Bulletin 29.) Price, 10 cents.

Road Materials of Southern and Eastern Maine. (Roads Bulletin 33.) Price, 20 cents.

Examination and Classification of Rocks for Road Building, Including the Physical Properties of Rocks with Reference to their Mineral Composition and Structure. (Roads Bulletin 37.) Price, 15 cents.

Methods for the Examination of Bituminous Road Materials. (Roads Bulletin 38.) Price, 10 cents.

Constructing Macadamized Roads. (Roads Circular 21.) Price, 5 cents.

Bitumens and their Essential Constituents for Road Construction and Maintenance. (Roads Circular 93.) Price, 5 cents.

Vitrified Brick Pavements for Country Roads. (Department Bulletin 246.) Price, 10 cents.

Use of the Split-log Drag on Earth Roads. (Farmers' Bulletin 321.) Price, 5 cents.

Selection of Materials for Macadam Roads. (Separate 204 from the Yearbook 1900.) Price, 5 cents. 